\title{
H orizonte de racionalidade acerca da dependência de drogas nos serviços de saúde: implicações para o tratamento
}

\author{
The horizon of rationality about drug dependency \\ in health services: implications to the treatments
}

Daniela Ribeiro Schneider ${ }^{1}$

1Departamento de
Psicologia, Centro de
Filosofia e Ciências
Humanas, Universidade
Federal deSanta Catarina.
Cidade Universitária
Trindade Caixa Postal 476.
$88040-900$ Florianópolis
SC.
danischneider@cfh.ufsc.br
Abstract This article refers to the research discussion based on methodology of content analysis, which aims at making explicit the horizon of rationality of the services provided for alcohol users and other drugs in the Great Florianópolis region, to contribute to the establishment of qualitative parametersin the evaluation of health services. It was verified that there is a hegemonic conception about the drugs dependence phenomenon as well as the way to intervene in this phenomenon, synthesis of different and, sometimes, contradictory rationalities. Themodel of this conception is based on the notion of disease, on the pursue for abstinence, on the struggle to control de addiction, operating medical-therapeutic and moral apparatus. $0 n$ the basis of this conception, there is a subjectivist, moralist and psychopathologizing perspective, constituting a historical and not very critical view of the social production around the use of drugs, grounded on a rationality of metaphysical predominance, even when blended with other rationalities such as the scientific. In this article we will discuss the importance of correlating the "horizon of rationality" in the health services with the problematic of effectivenessand efficiency of treatments on thearea of drugs dependency.

Key words Rationality, Drugs, Treatment, Alcohol and other drugs dependency, Evaluation of health services
Resumo 0 artigo refere-seà di scussão de pesquisa baseada em metodologia de análise de conteúdo, cuja meta é explicitar o horizonte de racionalidade dos serviços de aten ção aos usuários de álcool e outras drogas na Região da GrandeF Forianópolis, objetivando contribuir no estabelecimento de parâmetros qualitativos na avaliação de serviços de saúde. Verificou-se a existência de concepção he gemônica acerca do fenômeno da dependência de drogas e do modo de intervenção no fenômeno, síntesederacionalidades diversase, algumas vezes, contraditórias entre si. Tal concepção centra seu modelo na noção de doença, na meta da abstinência, no busca do controle sobrea adição, operando dispositivos médico-terapêuticos e morais. $\mathrm{N}$ as raízes desta concepção, encontra-se uma perspectiva subjetivista, moralista e psicopatologizante, constituindo-se em visão ahistórica e pouco crítica da produção social em torno do uso de drogas, pautada numa racionalidade de predomínio metafísico, ainda que mesclado com outras racionalidades como a científica. Discute-se a importância de correlacionar 0 "horizonte de racionalidade" dos serviços de saúde com a problemática da eficácia e eficiência dos tratamentos na área da dependência de drogas.

Palavras-chave Racionalidades, Álcool e outras drogas, Tratamento, D ependência de drogas, Avaliação de serviços de saúde 
Introdução

Qualquer atividade profissional ou organização de serviços tem necessariamente como substrato uma racionalidadeteórico-metodológica quenorteia sua atuação. Esse substrato, produto específico do processo sócio-histórico de cada época histórica1, , é função de um "horizonte de racionalidade" que fornece uma compreensão sobreo ser da realidade (ontologia), sobre o homem, a sociedade e as relações sociais (antropologia), assim como, na área da saúde, sobre os processos de saúde/doença, com seus parâmetros estabelecidos sobre "normalidade" ${ }^{3}$. Daí, desdobram-se asteorias médicas, psiquiátricas, psicológicas, entre outras, e suas propostas de intervenção no fenômeno que é seu objeto. Portanto, a organização dos serviços, os processos de intervenção, as atividades técnicas desenvolvidas na área da saúde são estabelecidas a partir desses substratos.

Tais concepções estabelecem, tanto para os profissionais de saúde, quanto para os usuários, 0 entendimento sobre o sofrimento, bem como sobre o campo de possibilidades de intervenção na situação de saúde/doença. N este sentido, tal horizonte de racionalidadeinterfere diretamente quer na prática profissional, quer no engajamento dos pacientes nos processos de tratamento, na medida em que conforma sua concepção acerca da problemática, bem como sua crença na possibilidadederecuperação. Demaneira geral, para os pacientes, segundo Luz e Tesser ${ }^{2}$, uma vez satisfeita minimamente a relação de cura, a orientação e a terapêutica recomendadas são aceitas, sem questionamentos.

Especificamente na área da atenção à dependência de álcool e outras drogas, a interferência do horizonte de racionalidade sobre os processos detratamento, sobrea inteligibilidade do problema, bem como sobre o engajamento do usuário, é ainda mais marcante, devido ao fato de estarmos lidando com um fenômeno de saúde em que as dimensões antropológica, sociológica e psicológica são variáveis definitivamente constitutivas. Dessa forma, a mediação semiótica ${ }^{4}$ é parte integrante da constituição do problema da relação entre o sujeito, a droga e seu padrão de uso. 0 tema da dependência de drogas é, portanto, atravessado por polêmicas e desafios teóricos e epistemológicos ocasionados pelas inúmeras contradições que por ele perpassam, bem como pela complexidade de inter-relações nele envolvidas (sociais, psicológicas, políticas, orgânicas, etc.), dificultan do a delimitação do fenômeno, se comparar com a área da saúde que utiliza parâmetros mais propriamente orgânicos.
Um discurso ou concepção torna-se dominantequando se converteem senso comum, sendo assim naturalizado, ocultando suas determinantes de gênese ${ }^{5}$. Como afirma Luz e Tesser ${ }^{6}$, ocorre uma espécie de obscurecimento do polê mico e tortuoso caminho de construção desse saber, fazendo com que a sua verdade apareça como uma evidência. Contemporaneamente, na área da dependência de drogas, conforme se verifica na literatura especializada ${ }^{5,7-9}$, certas concepções tornaram-se dominantes, especialmente aquelas que centram seu modelo na noção de doença, na meta da abstinência, na busca do controle sobre a adição, operando dispositivos mé dico-terapêuticos e morais. A fim de compreendêla contextualizadamente, épreciso desvelar os caminhos de construção desta concepção, descendo às suas raízes sociológicas e epistemológicas, verificando os sistemas de racionalidades que a sustentam.

Sistemas deracionalidades e horizonte de racionalidade

O homem é um ser racional; essa é sua característica distintiva dos animais comuns e a que lhe confere sua humanidade. A racionalidade é a mediação do homem com a sua história e seu devir ${ }^{10}$. 0 homem, ao se organizar material e sociologicamente para realizar suas finalidades de ser, ou seja, ao sefazer mediar pelas coisas e pelos outros em direção a um projeto de ser, produz a "razão". Isto porque o sujeito, para se reconhecer como tal, tem de se apropriar das ocorrências naturais ou sociais que o cercam e essa apropriação é mediada por um conjunto de conhecimentos, valores, juízos morais, saberes e práticas que, misturados no processo cultural, formam a racionalidade específica de um dado momento histórico. Desta forma, o horizonte de racionalidade é desdobramento do processo sócio-histórico. Essemovimento dialético, ocorrências materiais ou sociais - apropriação racional - ação humana - novas ocorrências, vai gerar a racionalidade de uma dada época, de uma dada civilização. Sendo assim, "qualquer civilização humana objetiva-se abrigada por uma abóbada de saber-de-ser universal" 10 .

O horizonte de racionalidade de uma época, quer dizer, esse saber-de-ser universal, objetivase em uma dada cultura, em um dado momento histórico, em um dado território, implicando a constituição dialética de uma infinidade de racionalidades singulares (de uma família, de um campo profissional, de uma dada instituição, de 
um sujeito), na medida em queo universal éapropriado pelos diferentes sujeitos de maneira singular. Um homem não é jamais um indivíduo. É melhor chamá-lo de um universal-singular: totalizado euniversalizado por sua época, el ea retotaliza reproduzindo-se nela como singularidade. Universal pela universalidade singular da história humana, singular pela singularidade universalizantedeseus projetos, ele exigeser estudado simultaneamente pelas duas extremidades ${ }^{11}$. Portanto, cada sujeito está comprometido ontologicamente com os outros, pois ele faz a história assim como os outros também a fazem.

Esse horizonte de racionalidadeé constituído por uma síntese antropológica de diferentes sistemas de racionalidades, que são as formas específicas que a humanidade construiu para produzir seus conhecimentos. Cada modo de produção de conhecimento éautônomo econstrói uma forma singular de produzir sua racionalidade. Em termos universais, temos quatro grandes sistemas: o teológico ou religioso, o metafísico, o político e o científico, cada um com seu modo específico de produção de seu conhecimento.

Segundo a definição de Bertolino ${ }^{10}$, a racionalidade teológica é elaborada a partir de coordenadas conceituais ou lógicas, sustentadas em revelações divinas de dado profeta e em dogmas teológicos, objetos de crença religiosa. Tal racionalidade tem especificidades conformeas comunidades de credo, por exemplo, cristãos católicos, cristãos protestantes, cristãos evangélicos, maometanos, islâmicos, budistas, etc. A racionalidade religiosa ou teológica aplica-se sempre como uma doutrina moral.

Já a racionalidade metafísica é elaborada a partir de coordenadas conceituais ou lógicas, sustentada em um ponto de partida logicamente necessário. A racionalidademetafísica presta contas ao próprio sistema que a mantém, sendo por ele garantida, sustentando-se em um jogo lógico, formando aquilo que costuma conceituar-se como circularidade hermenêutica. Instaura, assim, um conjunto de crenças profanas, sustentando-se, com isso, em uma perspectiva dogmática. Especifica-se em diferentes racionalismos, como éo caso dos ideal ismos, realismos, materialismos, espiritualismos, entre outros.

A racionalidade política é formada por coordenadas conceituais ou lógicas, girando em torno da articulação de interesses práticos de organização da pólis, da organização em torno deum projeto para a sociedade, constituindo-se, conforme as especificidades, em diferentes sistemas político-ideológicos, como o conservadorismo, o liberalismo, o capitalismo, o socialismo, etc.
A racionalidade científica, por fim, tem como base coordenadas teórico-metodológicas e não lógicas, garantidas pela descrição, observação, verificação de fenômenos naturais ou humanos, estabelecidas pela articulação interdisciplinar. Sustentando-se em fenômenos observados com rigor metodológico, deve ter controle dos processos de produção do conhecimento e controle de resultados, chegando a formar diferentes sistemas teórico-metodológicos.

Tais sistemas de racionalidades, constituídos demodo específico epeculiar, são apropriados pelos coletivos sociais, bem como pelos sujeitos singulares, que os mesclam e sintetizam, convertendo-osem saber-de-ser coletivo. Sendo assim, uma dada cultura, uma prática profissional, um sujeito singular transcendem a todas essas racionalidades específicas que estão colocadas em seu contexto, através de arranjos sociológicos, realizando uma síntese deles em seu saber-de-ser singular.

Dessa forma, para conhecer a racionalidade a respeito das drogas e de sua dependência, em certa época eem certo contexto clínico, énecessário verificar quais os sistemas de racionalidade que temos a nossa disposição e de que forma os serviços de saúde, bem como seus profissionais e usuários, apropriam-se deles e realizam a síntese em termos da sua racionalidade específica. Poderíamos falar, de certo modo, de racionalidades médicas, como postula Luz e Tesser ${ }^{2,6}$, enquanto um conjunto integrado e estruturado de práticas e saberes na área da saúde. 0 horizonte de racionalidade torna-se critério qualitativo para avaliação de serviços de saúde.

O N úcleo de Pesquisas em Psicologia Clínica da Universidade Federal de Santa Catarina (PSI CLIN/UFSC), desde 2002, desenvolve pesquisas na área de avaliação de serviços de atenção à dependência de álcool e outras drogas. Esta pesquisa, ora descrita, investiga o horizonte de racionalidade de tais serviços na Grande Florianópolis, com o objetivo de contribuir na avaliação qualitativa dos mesmos.

\section{Aspectos metodológicos}

O projeto foi aprovado no Comitê de Ética de Pesquisas com Seres Humanos da UFSC, sob $n^{\circ}$ 065/2005.

0 universo de serviços de atenção à dependência de substâncias psicoativas na Região da Grande Florianópolis, no momento da coleta de dados (2005), contava com 28 instituições, divididas entre hospitais, ambulatórios, comunidades terapêuticas, clínicas, centrais de grupos de 
ajuda mútua e programas de redução de danos. Naquele momento, ainda não havia sido fundado o CAPS-AD de Florianópolis, que só foi criado em 2006; portanto, esse não foi objeto da pesquisa. Responderam à pesquisa vinte serviços, entre eles: cinco ambulatórios, trêshospitais, uma clínica especializada, dois grupos de ajuda mútua, sete comunidades terapêuticas e dois programas de redução de danos.

Os instrumentos utilizados para a coleta de dados foram: a) questionário com questões fe chadas; b) entrevista semi-dirigida, com al gumas questões abertas. São os dados desta que serão apresentados e discutidos neste artigo. Os respondentes foram os responsáveis técnicos ou coordenadores dos serviços,

\section{M etodologia da anál ise de dados}

Para a análise dos dados das entrevistas, foi utilizada a metodologia qualitativa da análise de conteúdo, segundo o modelo sugerido por Olubué naga ${ }^{12}$. N essa perspectiva, compreende-se que 0 texto (a transcrição das entrevistas realizadas) sempreimplica um contexto, ou seja, um conjunto desentidos, significados, racionalidades subjacentes às concepções explicitadas pel os responsáveis técnicos ou coordenadores daqueles serviços.

Aqui serão analisadas as respostas transcritas e categorizadas à seguinte questão aberta feita na entrevista: "Na perspectiva dos profissionais desta instituição, o que acontece com as pessoas para que elas se tornem dependentes de álcool ou outras drogas e necessitem procurar tratamento, ou seja, quais são as determinantes destefenômeno?"

Foram dadas 55 respostas diretas à pergunta, que foram agrupadas em catorze categorias abrangentes. Tais categorias passaram por uma verificação em termos de clareza, significação, exaustão, proximidade de conteúdo, resultando no texto final com nove categorias de respostas.

Realizou-se, por fim, sua descrição e discussão a partir de uma grade analítica (ver Quadro

1), composta a partir da literatura especializada na área, abarcando dois aspectos: 1) os chamados "modelos de análise" de abordagem e tratamento da dependência de drogas, utilizados para categorizar as diferentes concepções ou explicações do fenômeno do uso das drogas e de sua dependência e seus desdobramentos para o tratamento em termos da discussão contemporânea-9,13-15; 2) os "sistemas de racionalidade", referenciados em postulações de especialista da área da antropologia da ciência ${ }^{10}$, que permitem explicitar as raízes ontológicas e antropológicas dos modelos e concepções encontradas nos serviços e, a partir disso, constatar o "horizonte de racionalidade" de cada serviço específico. Sendo assim, este último aprofunda a discussão dos "modelos de análise", em termos dos seus pressupostos filosófico-epistemológicos.

\section{Descrição ediscussão dos resultados}

As categorias resultantes da questão aberta sobre a concepção, por parte da equipe técnica, do fenômeno da dependência de álcool e outras drogas, foram organizadas por tipo de serviço respondente, o que permitiu estabelecer discussões acerca das racionalidades hegemônicas nos diferentes serviços especializados na Grande Florianópolis.

A grande maioria dos serviços afirmou considerar a dependência como um fenômeno multideterminado ou, mais especificamente, um processo biopsicossocial (dezenove serviços utilizaram essa forma de argumentação entre os vinte respondentes). No entanto, o entendimento sobre o que são esses três diferentes aspectos (tripé) que constituem o fenômeno referido foi bastante divergenteentreas diversas instituições, demonstrando que sob um discurso hegemônico podem existir concepções variadas, muitas vezes incompatíveis entresi. Essas divergências vão desdeconcepções como: a) a dependência como uma doença, com claros componentes genéticos, que se torna recorrente e incurável; b) a dependência como um problema de reencarnação; c) a drogadição como produzida na ordem social, sendo concebida como uma escolha livre do sujeito no seu direito de cidadão, entre outras tantas. Portanto, impõe-se a necessidade de esclarecer as diferentes noções que sustentam esses argumentos díspares, apesar de, aparentemente, estarem todos sob um mesmo discurso ou rótulo.

$\mathrm{Na}$ análise detalhada dos argumentos acerca das determinantes da dependência, verifica-seum predomínio de uma visão psicologizante, pois a variável prevalente nesta concepção foi a atribuída à estrutura da personalidade do usuário (dezessete serviços), entendida em sua grande maioria em uma perspectiva subjetivista (atribuição de uma subjetividade autossustentada) e/ou moralista (subjetividade concebida a partir da relação com valores morais ou religiosos) sustentada em noções como "problemas de auto- afirmação", "sensibilidade", "falta de limites", "indisciplina mental", "falta de força de vontade", "busca inter- 
Quadro 1. Grade analítica.

\begin{tabular}{|c|c|c|c|c|c|c|}
\hline & & & Modelos & análise & & \\
\hline $\begin{array}{l}\text { Modelo jurí } \\
\text { - visão dualista } \\
\text { realidade-man } \\
\text { - redução da of } \\
\text { - ameaça aos u } \\
\text { punição aos tr } \\
\text { - pedagogia do } \\
\text { - princípios rep } \\
\text { (problema de p } \\
\text { - concepção de } \\
\text { como pecado, } \\
\text { e errado (usuár } \\
\text { droga é um ma } \\
\text { combatido. A } \\
\text { no sujeito em } \\
\text { com a droga } \\
\text { - ideal de pure } \\
\text { abstinência }\end{array}$ & $\begin{array}{l}\text { moral } \\
\text { ta } \\
\text { de drogas } \\
\text { s e } \\
\text { tes } \\
\text { r } \\
\text { vos } \\
\text { a) } \\
\text { adição } \\
\text {, certo } \\
\text { quea } \\
\text { r } \\
\text { e é } \\
\text { ação }\end{array}$ & 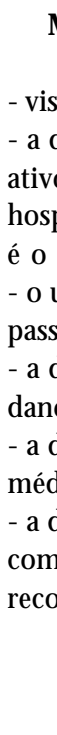 & $\begin{array}{l}\text { delo médico ou } \\
\text { saúde pública } \\
\text { biopsicossocial } \\
\text { ga é um agente } \\
\text { o indivíduo é um } \\
\text { deiro e o contexto } \\
\text { eio ambiente } \\
\text { lário é uma vítima } \\
\text { a ser curada } \\
\text { ga tem caráter } \\
\text { ga é um problema } \\
\text { gadição é tida } \\
\text { uma doença } \\
\text { ente e incurável }\end{array}$ & $\begin{array}{l}\text { Modelo } \\
\text { psicosoci } \\
\text { - o indivíduo é um } \\
\text { ativo na dependêr } \\
\text { - o contexto socia } \\
\text { definidor } \\
\text { - intervenção em } \\
\text { caso específico } \\
\text { - interação entre o } \\
\text { e usuário. } \\
\text { - a drogadição éti } \\
\text { fruto dos aspectos } \\
\text { psicológicos e soci } \\
\text { - hoje em dia os se } \\
\text { atenção à depend } \\
\text { sempre se dizem } \\
\text { psicossociais. }\end{array}$ & $\begin{array}{l}\text { ente } \\
\text { omo } \\
\text { os de } \\
\text { a }\end{array}$ & $\begin{array}{l}\text { Modelo sociocultural } \\
\text { - ênfase no contexto } \\
\text { - parte de como a } \\
\text { sociedade utiliza a droga } \\
\text { - a drogadição é fruto das } \\
\text { condições sócio, } \\
\text { econômicas e ambientais. }\end{array}$ \\
\hline Fonte & cher14 & & & & & \\
\hline & & & Sistema de & onalidades & & \\
\hline $\begin{array}{l}\text { Teol } \\
\text { - Coordenadas } \\
\text { ou lógicas } \\
\text { - Revelações di } \\
\text { (crenças religio } \\
\text { - Comunidade } \\
\text { - Doutrina mo }\end{array}$ & $\begin{array}{l}\text { eituais } \\
\text { dogmas } \\
\text { redo }\end{array}$ & $\begin{array}{l}-\mathrm{Co} \\
\text { con } \\
-\mathrm{Po} \\
\text { logi } \\
\text { (cre } \\
-\mathrm{Ga} \\
\text { siste } \\
\text { - Ra }\end{array}$ & $\begin{array}{l}\text { M etafísica } \\
\text { denadas } \\
\text { tuais ou lógicas } \\
\text { o de partida } \\
\text { nente necessário } \\
\text { as profanas) } \\
\text { ntido pelo próprio } \\
\text { a } \\
\text { onalismo }\end{array}$ & $\begin{array}{l}\text { Política } \\
\text { - Coordenadas cor } \\
\text { ou lógicas } \\
\text { - Articulação de ir } \\
\text { práticos de organi } \\
\text { pólis } \\
\text { - Ideologia }\end{array}$ & uais & $\begin{array}{l}\quad \text { Científica } \\
\text { - Coordenadas teóricas e } \\
\text { metodológicas } \\
\text { - Garantida pela } \\
\text { interdisciplinaridade } \\
\text { - Aplica-se em fenômenos } \\
\text { naturais ou humanos } \\
\text { - Controle de resultados } \\
\text { - Hipotética ou teórica }\end{array}$ \\
\hline Fonte & & & & & & \\
\hline & & & Tipos o & jiços & & \\
\hline Hospitais & $\begin{array}{l}\text { Clínic } \\
\text { especializ }\end{array}$ & & $\begin{array}{l}\text { Comunidades } \\
\text { terapêuticas }\end{array}$ & Ambulatório & GAN & Redução de danos \\
\hline
\end{tabular}

na de realização". Também significativa as respostas em perspectiva psicopatologizante (subjetividade considerada a partir de problemas psicológicos ou psiquiátricos) (onze serviços), sustentada em noções como "dificuldade de lidar com o sofrimento ou frustração", "fuga da realidade", "forma de lidar com os problemas psicológicos", "comorbidade", "forma de lidar com problemas emocionais ou problemas sexuais".

Portanto, no aspecto "psico" do tripé do discurso hegemônico, destaca-se a perspectiva de culpabilização do usuário sobre seu problema da dependência, baseada numa concepção determinista (subjetivista, moralista, psicopatologizante) do fenômeno.

Outros argumentos referiam-se ao aspecto "social" do tripé, referendado no item "importância do contexto social do indivíduo na constituição da dependência" (treze serviços). A maioria dos serviços citou o contexto social como a variável fundamental na dependência, porém geralmente associado às questões de personalidade. 
0 entendimento predominante sobre o contexto social é sustentado em uma perspectiva ambientalista (seterespostas), passando por noções como "influência do ambiente", "influência das más companhias", "problemas de educação no meio", etc. Verifica-se que essa variável, que poderia ser um contraponto à cul pabilização do usuário, serve na verdade, na maioria dos serviços, para referendá-la, na medida em que grande parte das re ferências concebem que 0 ambiente é também doentio, daí decorrer o problema do indivíduo. Dessa forma, incluem o contexto social em uma perspectiva que, segundo Patto ${ }^{16}$, reserva ao termo "ambiente" uma concepção acrítica e ahistórica, compatível, ao mesmo tempo, com uma visão biologizada da vida social e com uma definição etnocêntrica de cultura.

Outra variável, próxima da questão do contexto social, bastante significativa em termos numéricos (onze instituições) foi a da compreensão da dependência como decorrente de problemas na estrutura familiar. Essas concepções são sustentadas, em sua maioria, em noções psicopatologizantes, como as referentes à "falta de autoestima dos pais", "falta de autoridade paterna", "problemas decorrentes da separação dos pais", "hábito de beber dos familiares", "pais alcoolistas ou com histórico de dependência". D essas respostas, dez são associadas pelos serviços às questões da estrutura de personalidade. Poder-se-ia afirmar, parodiando novamente as reflexões de Patto ${ }^{16}$, que estemodo de compreender a relação com as famílias e sua culpabilização é um desdobramento da culpabilização dosusuários, só queagora localizado em seu ambiente familiar ecultural. É a conhecida "teoria da carência cultural", que seguindo o corolário da perspectiva liberal busca as determinantes dos problemas sociais, como 0 caso da drogadição, em aspectos como alta densidade habitacional, ausência dos pais, desinteresse dos pais, autoritarismo dos pais, ausência de hábitos saudáveis, etc., considerados variáveis independentes que levam ao uso abusivo de drogas. Aqui se vê repetir, novamente, a lógica referenteao aspecto do contexto social, já queos problemas no funcionamento familiar são tomados em perspectiva ahistórica e não dialética, servindo para referendar a concepção subjetivista, moralista e psicopatologizante predominante.

Ainda outras duas variáveis (ambas citadas por nove serviç̧os), são as referentes à dimensão biológica do fenômeno das drogas: a primeira refere-se à noção da dependência como doença crônica erecorrente, com determinantes orgânicas, neuroquímicas ou genéticas, ea outra com- preende a dependência como função das características intrínsecas das drogas. Essa visão vem somar-se às anteriores, formando um dos pilares que sustenta a racionalidade dominante. Ela serve para complementar a culpabilização do usuário, só que agora o usuário é "vítima" de uma doença, cujas determinantes são genéticas ou químicas.

A visão hegemônica que aparecesubjacenteà concepção biopsicossocial da dependência de drogas é assim, ao mesmo tempo, subjetivista, psicopatologizante, ora organicista, ora ambientalista. N a verdade, faz uma síntese de influências epistemológicas diversas, muitas vezes aparentemente contraditórias entre si. Ela apareceu na maioria dos serviços (dezessete entre vinte), ocorrendo pequenas variações intrínsecas às especificidades de cada serviço.

Poucos foram os serviços que fugiram ao predomínio da concepção acima descrita, entre eles um ambulatório e os dois programas de redução de danos, que trabal ham com uma noção histórica do fenômeno da dependência, na qual o contexto social é tomado em uma perspectiva mais crítica e a concepção da dependência em um enfoque menos psicopatologizante.

O impacto dessa visão hegemônica sobre a problemática do uso de drogas faz-se sentir na meta dos tratamentos, que em sua grande maioria (nos dezessete serviços acima citados) é a da abstinência, ou seja, a de que o paciente deve livrar-se em absoluto do uso de drogas, nem que para isto tenha que sacrificar parte de sua vida social. 0 passo fundamental para a recuperação é, assim, o imperativo da interrupção do uso, sob quaisquer circunstâncias, sem levar em consideração a função da droga no contexto de vida do sujeito naquele momento.

0 único modelo terapêutico quecritica explicitamente esses pressupostos hegemônicos e suas metas é o dos programas de redução de danos, que tem 0 entendimento de que 0 trabalho de intervenção no uso abusivo dedrogas não devese centrar na interrupção absoluta do consumo, mas sim na minimização das consequências danosas do uso de drogas à saúde em geral do paciente, sustentado na crítica da visão da dependên ciacomo doença ecom base em uma concepção de liberdade e cidadania na relação com as drogas ${ }^{17,18}$. Alguns autores situam, no entanto, a redução de danos não como uma perspectiva de superação do modelo hegemônico, mas como uma postura reformista dentro da lógica predominante ${ }^{19,20}$.

Essa diferença entre a visão hegemônica e a perspectiva da redução de danosé, na verdade, a 
réplica na área de drogas, das contradições dialé ticas naárea da saúdemental entrea tese psiquiátrica e a antítese antipsiquiátrica, aqui representada em sua vertente antimanicomial ${ }^{5,21}$, daí os embates que se fazem presentes hodiernamente entre a classe médica psiquiátrica e ou tros trabaIhadores da área da saúde mental sobre os modelos de atenção ao uso abusivo de drogas. 0 M inistério da Saúde vem adotando, nos últimos anos, a política da redução de danos, expressa na sua "política integral a usuários de álcool e outras drogas" 22. M esmo sendo oficial, a perspectiva deredução de danos não éhegemônica e sofre grande resistência por parte da classe médica, principalmente a psiquiátrica ${ }^{23}$.

A partir da grade de análise, podemos verificar, no que se refere aos modelos de análise, que predomina entre os serviços de atenção à dependência o modelo psicossocial (dezoito serviços entre os vinte respondentes), que pressupõe que o problema das drogas advém da interlocução entre os problemas psicológicos do usuário, a interação familiar, o aprendizado social, ao atribuir um papel ativo para o usuário na sua dependência eum papel de influência do ambiente social, sendo que 0 alvo da intervenção é a interação droga-indivíduo. Utilizam-se na metodologia técnicas de enfoque psicodinâmico ou comportamental, ou técnicas de dinâmica de grupo, procurando modificar a relação do usuário com a substância da qual é dependente, modificando seu padrão de uso, visando à abstinência. 0 caminho para essa modificação passa por mudanças comportamentais do usuário em suas interrelações. $\mathrm{N}$ a verdade, esse modelo vem mesclado com outros, estando presente em quase todos os tipos de serviços.

Logo em seguida aparece o modelo médico (onze serviços), no qual a drogadição évista como doença crônica e recorrente, de fundo genético, biológico e/ou neuroquímico. 0 dependente é 0 pacienteque deveser tratado, sendo a droga considerada 0 agente definidor do processo da de pendência. 0 tratamento implica a modificação do padrão de uso, visando à abstinência total. Essemodelo épredominantenos hospitais, clínicas e alguns ambulatórios, mas aparece em outros serviços como alguns grupos de auto-ajuda e comunidades terapêuticas.

Os dois modelos acima descritos se superpõem em muitos serviços, numa perspectiva de complementaridade, apesar de certas contradições aparentes entre eles.

Também ésignificativo o número deserviços que se pautam no modelo jurídico-moral (nove serviços), no qual prevalece uma visão maniqueísta entre o indivíduo e a droga, sustentada em princípios morais e repressivos. A ênfase éa culpabilização do usuário, que deve modificar seus valores e sua vida social, adaptando-se às regras de boa convivência humana, pois o problema é que ele se deixou corromper pelo "grande mal" que é a droga. Esse modelo está presenteem boa parte das comunidades terapêuticas, geralmente organizadas por entidades de cunho religioso e grupos de ajuda mútua.

0 modelo sociocultural, mais crítico em relação à concepção hegemônica, concebe a drogadição como fruto das contradições sociais, econômicas e ambientais e sua interven ção é realizada no contexto do usuário de droga. A ênfase dessa concepção é modificar o padrão de uso da substância, intervindo nas determinantes sociais que levam ao uso abusivo, visando ao controle dos danos gerados pelo abuso das substâncias, mas não necessariamente sua abstinência total. Tem uma ênfase na ação preventiva. Esse modelo aparece somente em quatro serviços, sendo dois programas de redução de danos, um ambulatório e um hospital, sendo que nesteúltimo seu discurso aparece mesclado com o modelo médico.

É preciso discutir como épossível a mescla de modelosdeexplicação eintervenção aparentemente diferentes entre si. Para tanto, devemos descer às raízes da construção desses modelos, ou seja, aos pressupostos que os sustentam. Dessa forma, discutiremos, a partir da grade de análise, os sistemas de racionalidade que fundamentam tais saberes e práticas sobre o problema das drogas.

Sendo assim, no que se refere aos sistemas de racionalidade, podemos destacar que predomina no horizonte teórico-metodológico dos diferentes serviços especializados no atendimento aos usuários de álcool e outras drogas da GrandeFlorianópolis, a racionalidade metafísica (dezessete entre vinte serviços), implicando uma concepção determinista da dependência de drogas, baseada em princípioslógico-dedutivos, racionais. A maioria das concepções dos serviços sobre a drogadição encontram-se nesse horizonte de racionalidade, na medida em que se baseiam: a) ou em concepções morais sobre a drogadição, sustentadas em crenças profanas (crença na dicotomia bem versusmal como valor intrínseco ao homem, apologia de uma sociedade harmônica, da existência valores a priori a serem respeitados, etc.); b) ou em concepções subjetivistas, cuja concepção ontológica eantropológica estão pautadas em um determinismo idealista, sustentado no mito de um psiquismo autossustentado, no qual o que 
define o ser do sujeito são seus valores internos, seu "caráter" e a busca do autoconhecimento, que se expressam na noção de que todas as ações de vem partir da valorização da personalidade (autossustentada) do sujeito; c) ou ainda, em uma visão ambientalista, cuja crençaéno mito deuma natureza que tem suas razões a priori e que moldam ao homem através do determinismo social. Segundo alguns críticos ${ }^{24}$, essa visão se define por uma busca contínua de se aproximarem das ciências naturais, isto é, da transposição de conceitos de âmbitos muito diversos sem justificativa epistemológica consistente. Dessa forma, utilizam conceitos ahistóricos e associais para explicar a realidade humana, perden do a dialética constitutiva dessa realidade.

Em segundo lugar, aparece a racionalidade científica, presente em nove das instituições, que afirmam pautar suas concepções em estudos, pesquisas eintervenções científicas, principalmente as de cunho psiquiátrico, comportamental e da neurociência. Segundo a Organização Mundial de Saúde, em seu relatório "Neurociências: consumo e dependência de substâncias psicoativas", os progressos atingidos pela pesquisa em neurociências mostraram que a farmacodependência éum transtorno crônico, recorrente, com uma base biológica egenética, enão uma simples falta de vontade ou um desejo de se libertar ${ }^{25}$. Essa noção da dependência como doençaéo princípio fundamental do modelo médico, dito científico, que se desdobra principalmente em intervenções realizadas em perspectiva comportamental (terapia cognitivo-comportamental, prevenção à recaída, etc.).

Desta forma, a concepção metodológica que se desdobra dessa racionalidade é a de que, sendo a dependência uma doença incurável, a única intervenção que pode ser feita é na direção de controlar o comportamento, já que não será possível superar o problema ou resolver as contradições que levam à relação abusiva com as drogas, pois a pessoa será sempre um doente. Para tanto, o dependente tem de passar a sua vida em estado de alerta em relação às drogas, evitando qualquer ambiente ou pessoa eliciador do mesmo, evitando o uso, ainda que social.

A presença dessa racionalidade faz-se sentir nos serviços de cunho tipicamente médico-psiquiátrico, como as clínicas ehospitais, quese sustentam fundamentalmenten essa noção enos dispositivos clínicos e terapêuticos que dela se desdobram. No entanto, outros serviços que não são tipicamente psiquiátricos, como grupos de ajuda mútua e comunidades terapêuticas, pau- tam-se nessa noção da dependência como doença, tomada como uma certeza-de-ser, por advir do conhecimento médico-científico, servindo de base para suas intervenções jurídico-morais e psicossociais.

No entanto, a concepção da dependência como doença crônica e recorrente de origem genética é bastante questionável em sua cientificidade, na medida em que se pauta em uma concepção determinista, decunho organicista. N esse caso, vemos predominar a racionalidade metafísica mesmo dentro do modelo médico, travestida de um caráter científico. Segundo Luz e Tesser ${ }^{6}$, as entidades doen ças são os constructos teórico-operacionais em torno dos quais gira toda a abordagem da biomedicina. Devido ao excesso de importância metodológica que converge para elas, as doenças tornaram-se, para efeitos práticos, ontol ogizadas, ou seja, são tão profundamentedefendidas queadquirem um empenho metafísico epassam a dominar todo o proceder investigativo.

Essa perspectiva, dita científica, busca justificar-se por ter sustentação em pesquisas e em terapêuticas baseadas em evidências, que se pautam em verificações empíricas, sustentadas em análises estatísticas. Aqui, há uma confusão entreo método empírico, baseado nos procedimentos de descrição da realidade e sua avaliação em termos de dados estatísticos, com o método propriamente científico, no qual o empírico é só o primeiro passo, pois a ciência objetiva ir além da descrição e chegar à verificação das condiç̧ões de possibilidade de ocorrência do fenômeno. Desta forma, considerar o empírico como sinônimo de científico é um reducionismo. Deve-se questionar, portanto, o modo de proceder dessas pesquisas, pois tem como pressuposto uma noção determinista de fenômeno, principalmente dos aspectos psicológicos. Outros autores ${ }^{9,26}$ corroboram com essas críticas, argumentando que a psiquiatria contemporânea vem utilizando um modelo científico positivista, que realiza simplificações inaceitáveis. 0 padrão defendido da dependência como doença crônica e recorrente é passível, portanto, de críticas, por se sustentar em concepções genéticas controvertidas, que não abrangem a maior parte dos casos, afirmam tais autores. M asur ${ }^{27}$ demonstra, após uma revisão de pesquisas na área, que não existe nenhum estudo conclusivo a respeito da determinação biológica do alcoolismo, por exemplo.

Vale aqui fazer uma citação que deixa claro os interesses envolvidos no uso da ciência como legitimadora de ações sociais que servem a interesses diversos. 
0 processo de transformar questões sociais em biológicas ébastante conhecido na história da humanidade. Nos momentos de grande tensão social, demovimentos reivindicatóriosimportantes, a resposta da sociedade sempre foi biologizar as questões sociais que se haviam transformado em foco de conflito. N esse processo, sempre houve o respaldo da ciência de matriz positivista, Cujos interesses coincidem com os de uma determinada classe social. Ao biologizar as questões sociais, atingem-se dois objetivos complementares: isentar de responsabilidade todo o sistema social, inclusive em termos individuais e "culpabilizar a vítima". Talvez por aí se possa entender por que essa concepção de ciência e seus resultados são tão facilmente aceitos e disseminados pela sociedade, atémesmo pelas próprias vítimas desta ideologia apresentada como ciência²8.

Poder-se-ia correlacionar tais questões à reflexão de Patto ${ }^{16}$, pois tal como na área das dificuldades de aprendizagem, os pesquisadores e técnicos que trabal ham na área de drogas ficam, muitas vezes, alheios às questões da ideologia e das relações de poder que reproduzem enão conseguem identificar que tais aspectos estão entranhados no próprio corpo de sua dita ciência, gerando "um conhecimento científico queleva apenas ao reconhecimento-desconhecimento do que se propõe desvendar". Aqui exatamente está a falácia dessa racionalidade que se pretende científica, mas que não faz mais do que andar em círculo (hermenêutico), já que tem como ponto de partida certos pressupostos, dados a priori, utilizando-se de recursos metodológicos (pesquisas) visando comprová-los, exatamentecomo faz a lógica metafísica. Sendo assim, tais pesquisas confirmam aos técnicos a propriedade de sua visão preconceituosa a respeito dos usuários de drogas e de suas famílias, impedindo-0s, assim, de olhar para a situação das drogas e para a sociedade onde vivem com ol hos mais críticos.

A racionalidade teológica é a racionalidade típica dos modelos jurídico-morais, que muitas vezes se misturam às crenças profanas, da racionalidade metafísica. Fundamentam concepções como as da crença em um poder superior, ou a crença em um Deus, que dita os mandamentos a serem seguidos. N esse caso, a drogadição é entendida como um desvio dos valores religiosos ou morais, a partir do queo sujeito, influenciado pelas "forças do mal" por ter abandonado sua espiritualidade, tem que se redimir de seus erros e pecados. A terapêutica consiste em o usuário assumir seus erros, voltar a viver uma vida regrada, de respeito ao seu semelhante, voltando- se para a espiritualidade. Essa racionalidade aparece em sete instituições (07/20), entre as comunidades terapêuticas, grupos deajuda mútua, que ainda que não pertençam a uma comunidade de credo específico, têm como pressuposto a crença em uma força superior.

A racionalidade política postula que as determinantes do consumo de drogas são de ordem social e cultural, em que o indivíduo tem direito ao uso das substâncias psicoativas. A questão do abuso de drogas e seus impactos (agravos sociais que dele decorrem) são problema de saúde pública, devendo ser respeitados os direitos de cidadania e 0 acesso aos cuidados da saúde integral para os usuários. Essa racionalidade apareceu somente em três instituições da Grande Florianópolis. Tal concepção fundamenta os serviços que têm uma perspectiva que entra em choque com a concepção hegemônica acima descrita, sendo sua crítica tomada, basicamente, em uma perspectiva política. Ela representa na área das drogas, como vimos acima, o mesmo papel do movimento antimanicomial na área geral de saúde mental, impondo-se como antítese ao modelo médico-psiquiátrico emanicomial (sustentado na internação e abstinência).

Resumindo, o modelo hegemônico de atenção à dependência de drogas mescla o médicopsiquiátrico com o psicossocial e o jurídico-moral, sustentando-se em uma síntese de racionalidade metafísica, teológica e científica. M arlatt e Gordon ${ }^{8}$ demonstram como o modelo de doença (científico) funciona como um mandamento moral (metafísico), havendo na prática uma aliança destes dois modelos. Luz $^{29}$ discute que a biomedicina funciona a partir de hibridismos e sincretismos, coexistindo na cultura com outros sistemas que também operam na área da saúde. Estes "hibridismos" não são ao acaso. A questão agora é refletir como é possível tais "hibridismos"? Quais são suas consequências?

Segundo a literatura especializada, um dos maiores problemas na atenção à dependência é justamentea questão da aderência dos dependentes ao tratamento: são el evados os número de recaídas, abandonos, evasões e retornos aos serviços $^{30-32}$. Em torno de $60 \%$ a 80\% dos dependentes de droga que passam por algum processo de tratamento recaem no uso de drogas e não conseguem manter-se abstinentes, como é a sua meta, levando à questão da baixa resposta terapêutica ${ }^{33}$.

A maioria dos serviços estudados na presente pesquisa (dezesseteinstituições) referequeseus índices de abandono de tratamento e de recaída no uso de droga são altos, geralmente ultrapas- 
sando $50 \%$. Quando questionados sobre as razões dessa situação, a maioria das equipes técnicas argumenta o fato da dependência ser doença crônica e recorrente, somado aos aspectos da personalidade ou da psicopatologia dos pacientes ou de seus familiares, ou ainda da vulnerabilidade biológica às drogas, aspectos que retêm os usuários no quadro da dependência. Adotam, com isso, uma perspectiva determinista, seja de ordem subjetiva ou orgânica. Nenhum dos serviços estudados, ao buscar responder sobre o insucesso do tratamento, volta-se para seus próprios processos, questiona acerca de seus métodos, procedimentos e concepções. A resposta é fixada num círculo vicioso: o usuário tem problemas em função de ser vítima de predisposições genéticas, somadas aos traços de sua personalidade autossustentada; sendo assim, não se obtém sucesso no tratamento justamente por aquilo que leva a pessoa a procurar ajuda terapêutica. Torna-se, portanto, iatrogênico.

Tal ocorrência impõeo questionamento acerca dos fatores envolvidos na eficácia e eficiência dos tratamentos oferecidos à população. E aqui, permitimo-nos refletir sobre seus aspectos qualitativos e sua relação com a dimensão da racionalidade dos serviços.

\section{Conclusão}

De maneira geral, muitos serviços realizam uma combinação de diferentes modelos de análise do fenômeno da dependência de álcool e outras drogas, ainda que aparentemente contraditórios entre si, com claros desdobramentos para os modelos e métodos de tratamento ou de intervenção. Os modelos psicossociais, por exemplo, cuja ênfase está na relação en tre a situação do indivíduo e a de seu contexto social, interagem na interioridade de muitos serviços: ora com serviços sustentados no modelo médico, acarretando uma patologização tanto do social quanto do indivíduo, ora com modelo jurídico-moral, acarretando a culpabilização do usuário e de sua família. Há outros locais em que os modelos jurídico-morais adotam a noção da dependência como doença crônica e recorrente, típica do modelo médico, levando à patologização e culpabilização do usuário. O corre, assim, na maioria absoluta dos serviços, uma mescla demodelos deanálise da drogadição e, consequentemente, uma mistura de modelos de tratamento ou de intervenção no fenômeno.

Ao fundo dessa questão encontra-se a problemática do horizonte de racional idade que sus- tenta as concepções desses model os. Aqui vemos predominar, novamente, a mistura de racionalidades, sejam as metafísicas com as científicas, as metafísicas com as teológicas, as teológicas com as científicas, as metafísicas com as políticas, e assim por diante. Poderíamos afirmar que, quer seja a noção de doença crônica erecorrente, típica do modelo médico, quer seja a noção de um ambiente social nefasto cujas influências impelem 0 sujeito a um comportamento fora das normas, típica do modelo psicossocial, quer seja a de rendição a um poder superior, ou ainda a do imperativo de uma vida moral, típicas do modelo jurídico-moral, todas essas concepções têm em comum uma concepção determinista, ahistórica e não dial ética, típicas da racionalidade metafísica. Particularmente a visão médica, por se pretender científica, éa que entra em maior contradição, ao sesustentar em raízes deterministas emisturar-se com modelos morais. Daí a possibilidade dessas "mestiçagens", ainda que muitas contradições entre os modelos saltem aos olhos. Na lógica que sustenta essas proposições, há uma homogeneidade em termos de concepção ontológica e antropológica que permite essa persistente inter-relação.

Somente compreendendo essas interlocuções de racionalidades podemos compreender contradições como, por exemplo, a de serviços pautados e garantidos no modelo médico, com um quadro técnico multiprofissional, com médicos psiquiatras, psicólogos, assistentes sociais, enfermeiros, etc., com atuações pautadas em pesquisas e técnicas de vanguarda na ciência hodierna, mas que realizam em seu interior erecomendam a consecução de tratamento de seus pacientes em grupos de ajuda mútua (GAM), cujo modelo é eminentemente jurídico-moral, pautados em princípios morais e teológicos, sustentando essa parceria na justificativa de que são métodos que funcionam, pois auxiliam os pacientes a se manterem em abstinência. 0 contrário igualmente é verdadeiro, os GAM também recomendam os tratamentos médicos. Porque tais serviços "andam de mãos dadas" enem se questionam sobre tais contradições? Consideramos queéjustamente por não haver, na realidade, contradições em seus fundamentosúltimos, na medida em que constituem suas proposições baseados no sincretismo de racionalidades diversas, em última instância de ordem metafísica ou determinista. Dessa forma, em termos ontológicos e antropológicos, a maioria dos serviços se equivale nas concepções, tanto aqueles que se "pretendem científicos", quanto aqueles que são os defensores de uma moralidade humana a priori. 
Raras são as exceções a essa perspectiva he gemônica. Como vimos acima, são os programas de redução de danos que têm uma perspectiva mais crítica em relação aos modelos dominantes, sustentando-se em uma racionalidade política, ao argumentarem que uso de droga é uma questão deescolha, queo direito do usuário tem de ser respeitado, encarando o problema sob a ótica da cidadania, sendo quea intervenção tem de ser realizada na direção de minimização dos danos causados pelo consumo excessivo das drogas. No entanto, a redução de danos tem dificuldade de intervir nas pessoas que estão querendo interromper sua trajetória dependente. Quando isto ocorre, encaminham, contraditoriamente, para os serviços tradicionais, com seu modelo determinista.

Podemos, então, nos questionar acerca do impacto que essa concepção hegemônica produz nos resultados obtidos no processo de tratamento dos dependentes. Será que o predomínio de uma concepção da dependência de drogas em perspectiva subjetivista, moralista e psicopatologizante, em alguns casos ambientalista, bem como de uma visão ahistórica e pouco crítica da produção social em torno das drogas, que nos remetem para a hegemonia de uma racionalidade metafísica, determinista, não é um aspecto importante na obstacularização da compreensão do fenômeno e na consequente dificuldade de intervenção eficaz no fenômeno?

A noção de doença crônica e a imposição da meta da abstinência, já questionadas por muitos especialistas ${ }^{27}$, não seriam fatores que impõem aos usuários de serviços pautados nesta racionalidade, um descrédito no tratamento, já que está dado como fato consumado que ele não poderá alterar sua condição, mas tão somente controlá-la, tendo que, mesmo para isto, fazer um corte em sua história social (ou, como diz a máxima dos grupos de autoajuda, "evitar hábitos, lugares e pessoas")?

Desta forma, é preciso pensar a correlação entre a racionalidade sobre o fenômeno da dependência de drogas e a dificuldade de obter sucesso na maioria dos tratamentos, como forma de contribuir na avaliação qualitativa dos serviços de saúde.

\section{Agradecimentos}

Agradecemos aos responsáveis técnicos dos serviços pesquisados, quegentilmenteresponderam ao questionário e participaram da entrevista, viabilizando a consecução da pesquisa. Agradecemos às psicólogas Bianca Spohr e Carolina Leitão pelo auxílio na coleta dos dados da pesquisa, bem como a Eder Bráulio Leone, pela colaboração na discussão dos seus dados. 


\section{Referências}

1. Gutierrez $P, O$ berdiek H. Concepções sobre a saúde e a doença. In: Andrade S, Soares D, Cordoni L, organizadores. Bases da Saúde Coletiva. Londrina: UEL; 2001.

2. Luz $M$, Tesser $C$. Racionalidade médicas e integralidade. Cien Saude Colet 2008; 13(1):195-206.

3. Canguilhem G. 0 normal e o patológico. Rio de Janeiro: Forense-Universitária; 1982.

4. Vygostski LS. Pensamiento y Lenguaje. Obras Escogidas II. Madri: Visor; 1982.

5. Bravo 0. Discurso sobre drogas nas instituições públicas do DF. Temas em Psicologia da SBP 2002; 10(1):39-52.

6. Luz $M$, Tesser $C$. Uma introdução às contribuições da epistemologia contemporânea para a medicina. Cien Saude Colet 2002; 7(2):363-372.

7. Agra C. Droga: dispositivo crítico para um novo paradigma. [site da Internet]. [acessado 2005 set 16]. Disponível em: http://www.presidenciarepublica.pt/ $\mathrm{pt} /$ biblioteca/outros/drogas

8. M arlatt A, Gordon J. Prevenção da recaída. Porto Alegre: Artes M édicas; 1993.

9. Rezende M. Modelos de Análise do uso de drogas e de intervenção terapêuticas. [site da Internet]. [acessado 2005 set 03]. Disponível em: http:// www.unitau.br/prppg/publica/biocienc/downloads/ modeloanalisedroga-n1-2000.pdf

10. Bertolino P. Sistema de racionalidades. [site da Internet]. [acessado 2005 nov 21]. Disponível em: http:/ /www.nuca.org.br

11. Sartre JP. L'Idiot de la Famille: Gustave Flaubert de 1821 à 1857. Paris: Gallimard; 1971.

12. Olabuénaga JI. M etodología de la investigación cualitativa. Bilbao: Universidad de Deusto; 1999.

13. Anton DM. Conhecer e educar para prevenir. São Paulo: Scipioni; 2000.

14. Bucher R. Drogas e drogadição no Brasil. Porto Alegre: Artes M édicas; 1992.

15. Pillon S, Villar Luis M. Modelos explicativos para o uso de álcool e drogas e a prática de enfermagem. Rev Latino-am Enfermagem 2004; 12(4):676-682.

16. Patto MH. A produção do fracasso escolar. São Paulo: TA Queiroz; 1991.

17. Bastos $F$, M esquita $F$. Estratégia de redução de danos. In: Seibel S, Toscano Jr. A, organizadores. Dependência de drogas. São Paulo: Atheneu; 2000.

18. Brasil. Ministério da Saúde. Secretaria de Políticas de Saúde. Projeto Ajude Brasil: avaliação dos usuários de drogas injetáveis dos projetos de redução de danos apoiados pela CN-DST/AIDS. Brasília: Ministério da Saúde; 2001.

19. Marlatt GA. Redução de danos: estratégias práticas para lidar com comportamentos de alto risco. Porto Alegre: Artmed; 1999.

20. Rodrigues T. Política de drogas e lógica dos danos. Revista Verve 2003: 3:257-277.
21. Leone E. Balanço da Produção Acadêmica Brasileira no Campo da Saúde M ental - 1990/97. Revista de Ciências Humanas 2000; 4:45-53.

22. Brasil. M inistério da Saúde. Secretaria Executiva. Coordenação Nacional de DST/Aids. A Política do M inistério da Saúde para atenção integral a usuários de álcool e outras drogas. Brasília: M inistério da Saúde; 2003.

23. M oraes $M$. 0 modelo de atenção integral à saúde para tratamento de problemas decorrentes do uso de álcool e outras drogas: percepções de usuários, acompanhantes e profissionais. Cien Saude Colet 2008; 13(1):121-133.

24. Bonfim W. Epistemologia da comunicação $x$ senso crítico midiático. [site da Internet]. [acessado 2005 jun 15]. Disponível em: http://www.eco.ufrj.br/semiosfera/anteriores/semiosfera01/expressao/txtpens 2.htm

25. World Health Organization. Neurociências: consumo e dependência de substâncias psicoativas. [site da Internet]. [acessado abr 05]. Disponível em: http:/ /www.who.int

26. Szasz T, Savitt R, Tomás J. Psicologia del drogadicto. Buenos Aires: Rodolfo Alonso; 1972.

27. Masur J. A atual polêmica no tratamento do alcoolismo: beber controlado ou abstinência. Rev. Asso. Bras. Psiq. 1980; 2(1):73-77.

28. Collares CAL, M oyses MAA. Preconceitos no cotidiano escolar - ensino e medicalização. São Paulo: Cortez; 1996.

29. Luz M. Entrevista. [site da Internet]. [acessado 2008 jan 23]. Disponível em: http://www.lappis.org.br/cgi/ cgilua.exe/sys/start.htm?infoid $=165 \&$ sid $=20$

30. Marques ACPR, Buscatti D, Formigoni MLOS. 0 abandono no tratamento da dependência de álcool e outras drogas: como diminuir o fenômeno? JBDQ 2002; 3(1):17-23.

31. Pinsky I, Silva EA, Marques AC, Formigoni MLOS. Abandono do tratamento por dependentes de álcool e drogas: um estudo qualitativo dos motivos. Revista ABP-APAL 1995; 17(4):150-154.

32. Silva $E$, Ferri $C$, Formigoni ML. Situações de recaídas em pacientes dependentes de álcool e outras drogas durante 0 tratamento: um estudo preliminar. J. bras. psiquiatr. 1995; 44(6):311-315.

33. Ramos SP, Woitowitz AB. Da cervejinha com os amigos à dependência de álcool : uma síntese do que sabemos sobre este percurso. Rev. Bras. Psiquiatr. 2004; 26(Supl. 1):18-22.

Artigo apresentado em 14/02/2008

Aprovado em 20/12/2008

Versão final apresentada em 23/12/2008 